Voix et Images

voixetimages

\title{
Éclats et grâces de la Mauvaise Foi
}

\section{Renald Bérubé}

Volume 16, numéro 3 (48), printemps 1991

François Charron

URI : https://id.erudit.org/iderudit/200931ar

DOI : https://doi.org/10.7202/200931ar

Aller au sommaire du numéro

\section{Éditeur(s)}

Université du Québec à Montréal

\section{ISSN}

0318-9201 (imprimé)

1705-933X (numérique)

Découvrir la revue

\section{Citer cet article}

Bérubé, R. (1991). Éclats et grâces de la Mauvaise Foi. Voix et Images, 16(3),

545-549. https://doi.org/10.7202/200931ar d'utilisation que vous pouvez consulter en ligne.

https://apropos.erudit.org/fr/usagers/politique-dutilisation/ 


\section{Éclats et grâces de la Mauvaise Foi}

par Renald Bérubé, Université du Québec à Rimouski

Voici plus de mille ans que la triste Ophélie Passe, fantôme blanc, sur le long fleuve noir. Voici plus de mille ans que sa douce folie Murmure sa romance à la brise du soir. [...]

Ciel! Amour! Liberté! Quel rêve, ô pauvre Folle! Tu te fondais à lui comme une neige au feu;

Tes grandes visions étranglaient ta parole - Et l'Infini terrible effara ton oil bleu!

Arthur Rimbaud, «Ophélie”

Elle était d'une autre étoffe. Rien d'impur ne l'atteindrait, elle savait d'instinct, et peut-être un peu par son cher Hardy, qu'il y a de ces êtres dont 
les comportéments ne sauraient être soumis à l'aune de la morale commune, qui ont pour tâche, au contraire, d'en définir une nouvelle, plus haute, plus exigeante [...] - dont on pourrait rire si l'on ne savait que, tôt ou tard, ceux chez qui elles [ces idées] germent finissent par se casser la figure.

Et puisque ce narrateur, qui joue les Dieu le Père dans son nuage, s'est déjà beaucoup compromis, il te propose, lecteur, un nom pour cet état. C'est le complexe Rimbaud. Vous savez, ce poète français d'une petite ville étroite du Nord qui, pour changer la vie, rêva d'une langue qui serait de l'âme pour l'âme, accrochant la pensée et tirant, qui pressentait violemment la voile.

\section{Gérald Tougas, la Máuvaise Foi ${ }^{1}$}

'Ainsi donc, cher narrateur qui vous prénommez Marcel, ce lecteur, ayant inscrit les deux épigraphes que vous venez de lire, l'une comme l'autre vous étant sans doute familière et les deux réunies voulant déjà donner, vous vous en doutez bien, l'orientation de son compte rendu critique, c'est-à-dire de sa lecture' de la Mauvaise Foi - ce lecteur, vous le savez déjà, a choisi de s'adresser à vous. Comme pour répondre à votre interpellation, comme pour (vous) proposer à son tour sa lecture de ce petit documentaire (p. 16), de cette quête (p. 26), de cette espèce de journal (p. 39) que vous avez entrepris d'écrire et dont l'héroïne est Irène votre grande sœur tendrement aimée (p. 17), à qui vous avez voué un culte (p. 32); racontant l'histoire de cette sœur morte à vingt ans dans dès circonstances étranges, c'est aussi la vôtre, nous dites-vous, que vous entreprenez de raconter (p. 17). Et deux ou trois fois plutôt qu'une, ainsi que dans le Bruit et la fureur de Faulkner; car si vous employez le je dans la première partie (p. 9-85) de la Mauvaise Foi tout en confiant alors l'essentiel du récit de la vie et de la mort d'Irène à l'oncle maternel Philippe, le héraut de la saga familiale, son griot, son commentateur attitré, son porte-parole le plus autorisé (p. 49), ce qui vous oblige déjà à jouer du il ou du Marcel en parlant de vous, vous employez essentiellement le $i l$ dans les deuxième (p. 87-220) et troisième (p. 221-266) parties. Et alors, subtilement, par petites touches, le récit se modifie un peu, se transforme tout en demeurant le même, cela étant particulièrement mis en évidence quand les pages 234 et suivantes reprennent la narration de faits déjà racontés aux pages 35 et suivantes. Si je est un autre, pour parler comme Rimbaud, si le temps est sorti de ses gonds, pour parler comme Hamlet auquel vous faites allusion sans le nommer aux pages 201 et 219 , quelle réalité est la vraie, quel récit peut justement rendre compte du réel passé? Quelle 
foi, bonne ou mauvaise, accorder à la mémoire et à ses tendances sélectives, $\mathrm{au}(\mathrm{x})$ récit(s) d'après icelle? Et vous aurez peut-être noté, cher narrateur, que la quatrième de couverture de la Mauvaise Foi prête la phrase suivante à l'auteur du roman ainsi intitulé: Il a choisi de vivre au Québec pour la liberté du beau verbe sans complément de sa devise. Liberté de la mémoire et du verbe: Je me souviens - dans quelles circonstances, de qui, de quoi, comment?

Ce lecteur, cher narrateur prénommé Marcel, s'avise à ce moment-ci de son compte rendu écrit, même s'il en avait entendement depuis les premières lignes de son texte, que le voilà aussi devenu une sorte de narrateur s'adressant à d'autres lecteurs et lectrices. Envers qui il doit peut-être vous mettre en situation résumé qui pourrait se lire ainsi: Marcel Démontigny entreprend depuis le Québec un voyage en train qui le ramènera à son Manitoba natal. Voyage au cours duquel la rencontre de Christine, ma bilingue, bifide perfide (p. 41), accentuera, à cause des ressemblances physiques, le souvenir d'Irène; voyage qui se révèle recherche/ reconstitution du temps passé sinon perdu, voyage en train qui est l'occasion de modifications à la vulgate (p. 53) de l'oncle Philippe, s'agissant du récit de la vie et de la mort d'Irène; voyage qui est un Retour au pays natal selon le titre, en traduction française, du roman de Thomas Hardy, roman qu'Irène a lu au cours de ses études et dont l'un des personnages principaux, Eustacia Vye, est devenu le modèle (p. 106-108). Roman dont la brève lecture que vous en faites, au centre ou presque de votre journal-quête, cher narrateur, le place comme en abyme de la Mauvaise Foi. La spécularité utilise de multiples miroirs: le Retour au pays natal $(1878)^{2}$ a influencé le comportement d'Irène dont vous lisez, l'écrivant, le récit de la vie et de la mort bien des années après cette dernière, et au moment précis où vous-même retournez au pays natal. Et ce récit vous raconte aussi, vous nous l'avez dit. Multiples miroirs, temporalité multipliée aussi. À quoi vous savez bien qu'il faut encore ajouter ceci: si l'auteur de la Mauvaise Foi, roman selon le générique indiqué en page couverture, a placé des vers de Robert Frost en épigraphe à celui-ci, un autre poème du même auteur, "Stopping by Woods on a Snowy Evening "; que l'enseignante Irène va présenter à ses élèves, sera l'occasion, de lectures en interprétations par eux deux menées, du début de l'aventure (condamnée) Irène-Eric Driscoll; le narrateur écrit: Cette exégèse du plus pudique des poètes, qui affirmait qu'un poème devait commencer par des délices et s'achever sur la sagesse, fut le début de leur frénésie. (p. 128) Ô ironie de la pratique littéraire. dont la Mauvaise Foi fait si bel et si intelligent usage; et vousmême, narrateur prénommé Marcel, savez que votre frère se prénomme Renoir à cause des lectures (de Delly) de votre mère (p. 45), lectures qui expliquent aussi les quelques Gérald de votre village natal (p. 122). 
Bon. Hardy, Rimbaud, Frost, Proust (Marcel), Butor (la Modification) (?), Hamlet, Delly - nous voilà certes en compagnie littéraire nombreuse. Vous lisant aussi avec ses lectures genettiennes ${ }^{3}$ en tête, ce lecteur a souvent été sous le charme de votre dextérité chaleureuse et appropriée à utiliser aux meilleurs escients de très diverses pratiques narratives et transtextuelles; ce qui l'oblige à parler d'un autre livre encore, Faites ca et vous vivrez, qui a joué un grand rôle dans la formation d'Irène (p. 102 et 206). Livre de la morale étroite, de la mauvaise foi à laquelle vous réservez quelques-unes des pages les plus magnifiques et les plus dures de votre journal-quête, éclats qui sont des grâces; livre qui sera, ô ironie encore, comme à l'origine de la passion d'Irène pour le personnage d'Eustacia Vye: l'apostolat n'enseigne-t-il pas la défense des réprouvés (p. 106-107)? Au pays natal d'Irène - Québec en raccourci (p. 139), dit l'oncle Philippe -, les questions religieuses, et de même les questions linguistiques, se révèlent questions originelles. Ce qui nous vaut aussi ces pages à la fois pleines d'humour et d'ironie où l'anglais le dispute au français.

Retour au pays natal, recherche du temps passé/perdu: votre voyage en train, cher Marcel, n'est pas seulement le moment d'une quête, il est aussi le lieu mobile d'une enquête: Irène, dont le corps a été retrouvé dans les eaux du ruisseau Rouge un matin d'août, a-t-elle été la victime d'un accident, d'un meurtre, ou d'un... suicide? Sans doute n'est-ce-pas un hasard si la Mauvaise Foi, à un moment donné (précis), évoque un autre roman d'Earle Stanley Gardner (p. 232). Mais il y a encore autre chose, vous le savez bien, que voulaient déjà signaler les deux épigraphes. de ce compte rendu: la deuxième, qui vous cite, nous fait passer du cher Hardy d'Irène à ce que vous nommez le complexe Rimbaud. Or Irène meurt comme elle meurt, vous évoquez Hamlet sans nommer cette pièce où Ophélie meurt comme elle meurt, et Rimbaud a écrit un poème intitulé "Ophélie"; ce n'est sans doute pas moi qui vous apprendrez que Bachelard a consacré quelques belles pages à ce qu'il nomme le complexe d'Ophélie dans l'Eau et les rêves ${ }^{4}$. Tout cela étant, cher narrateur, vous comprendrez, entre vous et moi, que ce lecteur ait accordé une attention particulière à la déclaration suivante faite par l'auteur de la Mauvaise Foi à l'occasion d'une interview:

Il y avait le Chateaubriand des Mémoires d'outre-tombe, Saint-Simon mais pas tout, Proust et À la recherche du temps perdu, les poètes romantiques. Ici, Anne Hébert, Gaston Miron, Saint-Denys Garneau et Alain Grandbois. En anglais, Shakespeare évidemment. J'ai relu Hamlet presque une fois par année depuis quinze ans. ${ }^{5}$

Vous admettrez avec moi que, dans la perspective de cette lecture, et à ce moment-ci d'icelle, l'évocation d'une lecture continue de Hamlet 
ne puisse être passée... sous silence; de même, ce lecteur ne saurait oublier les auteurs et les œuvres que vous évoquez en page 25 de la Mauvaise Foi, en particulier votre compatriote Gabrielle Roy. Mais il nous faut arrêter et conclure.

En (vous) disant ceci: les qualités d'émotion liées à la superbe maîtrise de l'écriture, dans la Mauvaise Foi, font souhaiter que cette première œuvre ait une récidive, un prochain épisode, quel qu'en soit le sujet. Prochain Épisode, premier roman publié par Hubert Aquin et dans lequel je [s]'ophélise dans le Rhône ${ }^{6}$; à vingt-cinq ans d'intervalle, cher narrateur, la lecture du premier roman de Tougas a été l'occasion, pour ce lecteur, d'un émerveillement assez semblable à celui jadis ressenti à la lecture du premier roman d'Aquin. Continuez, cher narrateur, votre comptine qui cyclothymise (p. 24).

l Gérald Tougas, la Mauvaise Foi, Montréal, Québec/Amérique, 1990, 266 p. (Littérature d'Amérique).

2 Thomas Hardy, le Retour au pays natal (nouvelle édition revue et corrigée), traduction de Marie Canavaggia et introduction de Jean-Jacques Mayoux, Paris, Nouvelles Éditions latines, $1947,510 \mathrm{p}$.

3 Gérard Genette, Figures III, Paris, Seuil, 1972, 286 p. (Poétique); Palimpsestes. La Littérature au second degré, Paris, Seuil, 1982, 472 p. (Poétique). Vous le savez bien, cher narrateur, le livre est partout présent dans la Mauvaise Foi : Apporterait-elle un livre au lit? (p. 190)

4 Gaston Bachelard, l'Eau et les Rêves. Essai sur l'imagination de la matière, Paris, José Corti, 1964, p. 109-125. Et s'il ne redoutait l'opinion émise par la Mauvaise Foi sur la psychanalyse (p. 17), ce lecteur oserait émettre lidée qu'il serait fort intéressant de lire votre texte, cher narrateur, à la lumière des hypothèses de l'essai de Marthe Robert, Roman des origines et origines du roman, Paris, Gallimard, 1976, $365 \mathrm{p}$. (Tel, $\mathrm{n}^{\circ} 12$ ).

5 Réginald Martel, * Gérald Tougas, prix du Gouverneur général, fait un pèlerinage au pays natal w, dans la Presse, 27 janvier 1991, p. C5.

6 Hubert Aquin, Prochain Épisode, Montréal, CLF, 1965, p. 22. 